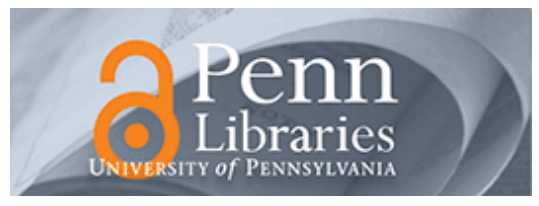

University of Pennsylvania ScholarlyCommons

$1-1-2011$

\title{
Role Thinking: Standing in Other People's Shoes to Forecast Decisions in Conflicts
}

Kesten Green

University of South Australia

J. Scott Armstrong

University of Pennsylvania, armstrong@wharton.upenn.edu

Follow this and additional works at: https://repository.upenn.edu/marketing_papers

Part of the Business Commons

\section{Recommended Citation}

Green, K., \& Armstrong, J. S. (2011). Role Thinking: Standing in Other People's Shoes to Forecast Decisions in Conflicts. Retrieved from https://repository.upenn.edu/marketing_papers/177

Suggested Citation:

Green, K. and Armstrong, J.S. (2011). Role Thinking: Standing in Other People's Shoes to Forecast Decisions in Conflicts. International Journal of Forecasting. Vol. 27(1). p. 69-80.

Publisher URL: http://dx.doi.org/10.1016/j.ijforecast.2010.05.001

This paper is posted at ScholarlyCommons. https://repository.upenn.edu/marketing_papers/177

For more information, please contact repository@pobox.upenn.edu. 


\title{
Role Thinking: Standing in Other People's Shoes to Forecast Decisions in Conflicts
}

\author{
Abstract \\ To forecast decisions in conflict situations, experts are often advised to figuratively stand in the other \\ person's shoes. We refer to this as "role thinking" because, in practice, the advice is to think about how \\ other protagonists will view the situation in order to predict their decisions. We tested the effect of role \\ thinking on forecast accuracy. We obtained 101 role-thinking forecasts of the decisions that would be \\ made in nine diverse conflicts from 27 Naval postgraduate students (experts) and 107 rolethinking \\ forecasts from 103 second-year organizational behavior students (novices). The accuracy of the novices' \\ forecasts was $33 \%$ and the experts' $31 \%$; both were little different from chance (guessing), which was \\ $28 \%$. The lack of improvement in accuracy from role thinking strengthens the finding from earlier research \\ that it is not sufficient to think hard about a situation in order to predict the decisions groups of people \\ will make when they are in conflict. It is useful instead to ask groups of role players to simulate the \\ situation. When groups of novice participants adopted the roles of protagonists in the aforementioned \\ nine conflicts and interacted with each other, their group decisions predicted the actual decisions with an \\ accuracy of $60 \%$.

\section{Disciplines} \\ Business

\section{Comments} \\ Suggested Citation: \\ Green, K. and Armstrong, J.S. (2011). Role Thinking: Standing in Other People's Shoes to Forecast \\ Decisions in Conflicts. International Journal of Forecasting. Vol. 27(1). p. 69-80. \\ Publisher URL: http://dx.doi.org/10.1016/j.ijforecast.2010.05.001
}




\title{
Role thinking: Standing in other people's shoes to forecast decisions in conflicts
}

\author{
Kesten C. Green* \\ International Graduate School of Business and Ehrenberg-Bass Institute for Marketing Science, \\ University of South Australia, Adelaide, SA 5000, Australia. (kesten.green@unisa.edu.au)

\section{J. Scott Armstrong} \\ The Wharton School, University of Pennsylvania, Philadelphia, PA 19104, U.S.A. \\ (armstrong@wharton.upenn.edu) \\ Forthcoming in the International Journal of Forecasting in 2011
}

\begin{abstract}
To forecast decisions in conflict situations, experts are often advised to figuratively stand in the other person's shoes. We refer to this as "role thinking" because, in practice, the advice is to think about how other protagonists will view the situation in order to predict their decisions. We tested the effect of role thinking on forecast accuracy. We obtained 101 role-thinking forecasts of the decisions that would be made in nine diverse conflicts from 27 Naval postgraduate students (experts) and 107 rolethinking forecasts from 103 second-year organizational behavior students (novices). The accuracy of the novices' forecasts was $33 \%$ and the experts' $31 \%$; both were little different from chance (guessing), which was $28 \%$. The lack of improvement in accuracy from role thinking strengthens the finding from earlier research that it is not sufficient to think hard about a situation in order to predict the decisions groups of people will make when they are in conflict. It is useful instead to ask groups of role players to simulate the situation. When groups of novice participants adopted the roles of protagonists in the aforementioned nine conflicts and interacted with each other, their group decisions predicted the actual decisions with an accuracy of $60 \%$.
\end{abstract}

Keywords: combining forecasts, evaluating forecasts, expert judgment, group decision making, organizational behavior, perspective-taking, role playing, simulated interaction, unaided judgment *Corresponding author 
Kesten C. Green (Ph.D., VUW, 2003) has previously published in the International Journal of Forecasting and was awarded "Best Paper" for his first paper on forecasting decisions in conflicts. Kesten established the conflictforecasting.com and publicpolicyforecasting.com Internet pages to encourage and disseminate research on these problems. He is also co-director of the forecastingprinciples.com Internet site. Kesten has advised the Department of Defense and the National Security Agency on forecasting, and his work has been covered in the London Financial Times, and the Wall Street Journal.

J. Scott Armstrong (Ph.D., MIT, 1968), Professor of Marketing at the Wharton School, University of Pennsylvania, is the author of Long-range Forecasting, the creator of forecastingprinciples.com, and editor of Principles of Forecasting (Kluwer 2001), an evidencebased summary of knowledge on forecasting. He is currently involved with attempts to show how evidence-based approaches can produce more accurate and useful forecasts for: (1) election forecasting, as described on PollyVote.com; (2) climate change forecasting, as described on theclimatebet.com; and (3) terrorism forecasting, as described on conflictforecasting.com. His book, Persuasive Advertising, was published in 2010 by Palgrave Macmillan. 


\section{Introduction}

We examined the problem of predicting the decisions people will make in important and novel conflict situations such as occur in politics, war, business, and personal affairs. To date, neither statistical nor casual models have been found to be feasible for such situations and so decision makers must rely on judgmental methods.

Conflict situations are often complex because they involve interactions between two or more parties with divergent interests. The complexity of conflicts provides fertile ground for hindsight bias. Experts delight in claiming that the proper decisions in conflict situations were obvious and that the actual decisions were misguided (Fischhoff 1975; Tetlock 2005).

One possible reason for decisions that appear absurd in retrospect is that people involved in conflicts fail to properly consider the viewpoints of other protagonists. Robert McNamara, head of the U.S. Department of Defense during much of the Vietnam War, drew this conclusion in the documentary, The Fog of War (Morris 2003). Experimental evidence shows that roles have a profound influence on people's behavior. Babcock et al. (1995), found that research participants presented with identical briefing material on a legal dispute made very different estimates of the money settlement a fair judge would hand down depending on whether they were given the role of lawyer for the defendant or for the claimant. Cyert et al. (1961) found that participants who were given the role of "cost analyst" made substantially different forecasts from those who were given the role of "sales analyst" even though they were given the same data.

One of the lessons McNamara said he had learned from his involvement in the Vietnam War was that he should have put himself in the shoes of the enemy. Galinsky and Mussweiler (2001) conducted an experiment on "perspective taking" that supports McNamara's belief. Participants in the experiment who thought about an opponent's situation when involved in mock negotiations tended to obtain better outcomes for themselves. Rothbart and Hallmark (1998), however, found in their experiment that participants who were asked to take on the role of either 
the defense minister or a citizen of one of two imagined countries involved in a conflict irrationally expected coercive strategies to be effective against the other country, but not against their own. Furthermore, Epley et al. (2004), in a series of experiments, found that in assessing the perspectives of others, people tend to anchor on their own perspective, and that their adjustments are incremental and partial even in the presence of incentives to make accurate assessments.

The broad advice to put oneself in the other person's shoes is commonly given to people who deal with conflict situations. For example, Nalebuff and Brandenburger (1996, p. 52) suggested, "To anticipate other players' reactions to your actions, you have to put yourself in their shoes and imagine how they'll play the game." We call this advice "role-thinking."

Given the potential benefit from following such advice, we investigated an approach to improving judgmental forecasting for conflicts by deriving forecasts from experts' analysis of information about the roles of the protagonists.

\section{Comparison of role thinking with unaided judgment and role playing}

In designing our research, we followed the multiple hypotheses approach advocated by Chamberlin (1890) by comparing the accuracy of plausible alternative methods. The methods we compared were role thinking, unaided judgment, and role playing. Given the uncertainty surrounding the prior research, we expected that our findings would be useful, no matter what they turned out to be.

The most common approach to forecasting decisions in conflict situations is unaided judgment. By unaided, we use the narrow definition of "judgmental procedures unaided by evidence-based forecasting procedures." This definition does not preclude drawing upon knowledge about the situation and other similar situations, and discussing the forecasting problem with other experts.

For the method that is the subject of this research, role thinking, to be useful for forecasting it would need to outperform unaided judgment. We expected that following the 
injunction to "put yourself in the other person's shoes" in a structured manner would improve people's ability to predict the decisions made by parties in conflict situations. And we expected that those with more expertise in conflicts would be better able to use role information to derive more accurate forecasts. However, we had reservations over the extent of any improvement in forecasting accuracy from the use of role thinking. We expected that trying to represent a novel conflict in a realistic way by thinking through the interactions of protagonists with different roles would prove to be difficult. Role thinking would likely result in a cognitive overload as the possibilities became enormous after only a few exchanges.

We had no expectations about the conditions under which role thinking would be relatively more effective, nor did we have the resources to conduct studies using large numbers of situations in order to asses the effects of different conditions.

We expected that utilizing role information by asking a group of people to each adopt the role of a protagonist and to then interact with those who adopted the roles of the other protagonists would be more realistic - and thus more effective - than asking experts to think hard about the roles and interactions (role thinking). Evidence on the validity of role playing dates back to the 1960s. Armstrong (2001) reviewed the evidence. For example, in response to the concern about the effects on subjects of participating in the Milgram experiments on blind obedience in the 1960s, researchers examined whether it might be sufficient to have participants role play as if they were subjects in an experiment. The outcomes of the role-plays matched up closely with the results in six out of seven laboratory experiments. The close matches occurred even though people using their unaided judgment were unable to predict the outcomes of some of these experiments - most notably the Milgram obedience studies themselves. Mixon (1972), for example, found that psychology experts, when presented with one of the experimental designs, predicted that about one percent of the subjects would be fully obedient, whereas, in the laboratory experiment, $65 \%$ were fully obedient. Thus, while we expected that role thinking 
would be superior to unaided judgment, we expected that role-playing of conflict situations, in the form of the simulated interaction method (Green 2005), would be superior to role thinking. ${ }^{1}$

\title{
Conflict situations for our test
}

To assess the accuracy of forecasts from role thinking, we employed the nine conflict situations that we used in our earlier research. The situations are briefly described in Table 1. Research participants were provided with one-to-two page descriptions of the situations and descriptions of the roles of major protagonists. The number of parties and roles that were described for each of the conflicts are indicated in brackets after each conflict name in the Table.

\section{Table 1: Brief descriptions of conflict situations}

\author{
Artists Protest $(2,4)$ : $\quad$ Members of a rich nation's artists' union occupied a major gallery and \\ demanded generous financial support from their government. What will be \\ the final resolution of the artists' sit-in? \\ Distribution Channel $(2,4):$ An appliance manufacturer proposed to a supermarket chain a novel \\ arrangement for retailing their wares. Will the management of the \\ supermarket chain agree to the plan? \\ 55\% Pay Plan $(2,4)$ : Professional sports players demanded a 55 percent share of gross revenues \\ and threatened to go on strike if the owners didn't concede. Will there be a \\ strike and, if so, how long will it last? \\ Journal Negotiations $(2,4)$ : Editors have asked their journal's publisher for better terms and have \\ received an unfavorable response. What agreement do the parties come to?
}

\footnotetext{
1 The early research of forecasting people's decisions by simulating the situation using interacting roleplayers used the term "role-playing" to refer to the method. Because the term "role playing" is widely used to refer to various techniques with purposes other than forecasting, we coined the term "simulated interaction" to refer the forecasting method. The distinctive newer name has the added advantage of reducing the chances of confusion in readers, for example with role thinking.
} 
Nurses Dispute $(3,5)$ : $\quad$ Angry nurses increased their pay demand and threatened more strike action after specialist nurses and junior doctors received big increases. What will the outcome of their negotiations be?

Personal Grievance $(3,5)$ : An employee demanded a meeting with a mediator when her job was downgraded after an evaluation by her new manager. What will the outcome of the meeting with the mediator be?

Telco Takeover $(2,4)$ : An acquisitive telecommunications provider, after rejecting an offer to buy the mobile business of another, made a hostile bid for the whole corporation. How will the stand-off between the companies be resolved?

Water Dispute $(3,5)$ : $\quad$ Troops from neighboring nations moved to their common border and the downstream nation threatened to bomb a new upstream dam. Will the upstream neighbor agree to release additional water and, if not, how will the downstream nation's government respond?

Zenith Investment $(2+, 9)$ : A board committee of a large manufacturer evaluated an investment in expensive new technology in the face of political pressure. How many new manufacturing plants will the corporation decide to commission?

Descriptions of two of the conflicts used in the previous research were prepared as the situations unfolded (55\% Pay Plan and Nurses Dispute); that is, the authors did not know what decision would be made when they wrote the descriptions. The other seven conflict situations were obscure and unlikely to be recognized or were disguised to prevent participants from recognizing them. In six instances, participants in our research on role thinking recognized the actual situation and those responses were excluded from our analysis.

There were two protagonists in eight of the situations and we used two roles to represent each of the two protagonists. By describing two roles per party the possibility of interactions within a party, as well as between the parties, was suggested to all participants and was accommodated among simulated interactions participants. Three situations involved a mediator 
and we used a single role for that person. The one situation with nine roles involved a committee without clear parties. All of the role descriptions were short. Here is an example from the Telco Takeover conflict:

\section{Role of Expander Telco Chairman - Al Exley}

Under you leadership for the past 15 years, telephone company Expander has grown rapidly with the acquisition of more than 250 companies. Recently, Expander was approached by Localville Telco. Localville wished to explore the possibility of selling its mobile phone business to Expander. You rejected the proposition, as Expander's policy is to be able to offer local telephone services as well as mobile when it moves into a new territory. Localville as a whole, however, would be an attractive acquisition (the companies' territories are complementary) and Expander has offered to buy Localville at a price-per-share that was $40 \%$ higher than the price prevailing at the time of the offer. So far, the Localville board has rejected this offer, but you and your son (Expander CEO, Brad Exley) believe Localville is a prize worth fighting for.

\section{Role thinking method}

The research participants, who are described below, were provided with descriptions of some or all of the situations and of all the associated roles. Appendix A provides the disguised description of one of the situations (Water Dispute) and the associated role descriptions. The actual Water Dispute situation involved two main parties, Syria and Iraq, in a dispute over the waters of the Euphrates River. Saudi Arabian government minister Sheik Yamani became involved in an attempt to avoid war between the two countries. The forecasting problem was to predict whether there would be a decision to go to war or to bomb the dam that was restricting the supply of water to Iraq, or to release more water.

Participants were led through the role-thinking procedure by a questionnaire that we

devised for the purpose (Appendix B). The questionnaires start with a briefing for participants that states: “A person's role can make a big difference to how he or she views a situation, so it 
can be difficult to predict what decisions will be made when people interact with each other. In the following table, please indicate which decision you think each party in the situation just described would prefer to be made and assess how likely it is that each party's preferred decision will actually occur."

Each questionnaire included a list of between three and six decisions that might plausibly have been made in the conflict situation. For example, in the case of the Nurses Dispute, research participants were asked to choose between (a) nurses' demand for an immediate 7\% pay rise and a 1-year term were substantially or entirely met, (b) management's offer of a 5\% pay rise and a 2year term were substantially or entirely accepted, or (c) a compromise was reached.

The questionnaire prompted participants to nominate which of the decisions each party in the conflict would prefer and why, how the party would go about trying to achieve the preferred decision, and the chances out of 10 that the party's preferred decision would be made. Finally, the questionnaire asked participants, having completed their analysis, to pick which of the decisions was most likely and why it might and might not occur. The process was intended to encourage participants to think hard about how the roles of the protagonists would affect their preferences and decisions.

There were two role-thinking sessions. One was at Victoria University of Wellington, New Zealand, in April 2005, and the other was at the Naval Postgraduate School in Monterey, California, in May 2005. Both sessions were conducted during class time, and no incentives were offered for participation.

\section{Research participants and their instructions}

Participants in the role-thinking session in Wellington were 103 students who were enrolled in a second-year organizational behavior course. The students were shown the following instructions on "Predicting Decisions in Conflict Situations," and had the balance of 50 minutes of class time 
to complete the task. In practice, most of the students took in the order of 20 to 30 minutes to do

so.

1. The research you are about to participate in is part of an investigation into how best to make predictions about the decisions people make in conflicts.

2. In front of you is the description of a real conflict situation. Other participants have descriptions of other situations; there are nine in total. The situations are disguised or obscure, so you are unlikely to recognize the actual situation.

3. Your task is to make judgments about the preferences and decisions of the parties involved in each situation.

4. Please read the description and then answer the questionnaire. Use the reverse side of the questionnaire if you need more space.

The students were mostly about twenty years of age. In order to obtain a measure of their expertise beyond what we could already assume from their youth and undergraduate status, we asked them to rate their specialist experience in conflict management and their experience with conflicts similar to the conflict situation they had been presented with. The median of the students' responses to these questions, using a zero-to-10-scale, was zero for both questions. We refer to these participants as "novices."

Participants in the role-thinking session at the Naval Postgraduate School at Monterey, CA, were 27 naval postgraduate students in a morning and an afternoon class each of two hours in length. They each had copies of material for one of nine sets of four conflict situations placed face down in front of them, and were given similar instructions to the undergraduate students except that they were asked to examine four situations and were given 30 minutes for each.

The naval postgraduate students were between 27 and 35 years of age and thus had in the order of 10 years of experience in the adult world compared to none for the undergraduate students. They were navy officers with commensurate responsibilities and substantially greater 
training for and experience with conflict situations than the young New Zealand university undergraduate students. The median of their self-assessed specialist conflict management experience ratings was 4 out of 10 which, when compared to the average zero rating of the undergraduate students, is consistent with the difference in the ages and experience of the two groups. The median of the postgraduates' ratings of their experience with similar conflicts was 1 (out of 10), which is consistent with them having spent their adult lives as navy officers when the conflict situations used in the research were diverse with only one (Water Dispute) having martial elements.

While it would have strengthened our findings if we had obtained the services of top experts in the domains of each of the conflicts we used as participants, we did not have the resources to do so. Importantly, however, there is little evidence that top experts are able to perform judgmental tasks better than people with more modest credentials (see, e.g., Green and Armstrong 2007a; Tetlock 2005). As for the relevance of the naval postgraduates' expertise for conflicts involving pay negotiations and commercial takeover battles, for example, we suggest that knowledge of conflicts from one domain may be sufficient to qualify its possessor as an expert because the problems that we gave them all involved predicting human behavior in conflict situations.

For the purposes of this research, then, we refer to the naval postgraduate students as "experts." We expected that if there were any gains to expertise in the use of the role-thinking method, they would show up in a difference between the accuracy of forecasts derived from their analysis and those derived from that of the young undergraduate organizational behavior students. 


\section{Findings from role thinking experiments}

We obtained 107 role-thinking forecasts from the novice participants for eight conflict situations and 101 forecasts from the expert participants for nine conflict situations. The data are available on the Internet ${ }^{2}$.

The un-weighted average accuracy of the experts' role-thinking forecasts was $31 \%$, which was slightly less accurate than the forecasts of experts who used their unaided judgment, at $32 \%$ (Table 2) ${ }^{3}$. Excluding the Journal Negotiations conflict - for which we had no experts' unaided judgment forecasts - from the calculations makes no difference to the figures at two significant digits. Novices' role-thinking forecasts were, however, on average for the eight conflicts common to both sets of results, more accurate at $33 \%$ than novices unaided judgment forecasts at $25 \%$. When novice and expert forecasts are pooled for all nine conflicts, role-thinking forecasts were on average somewhat more accurate, at 32\%, than unaided judgment forecasts at $27 \%$. Our expectation that use of a role-thinking procedure would improve judgmental forecasts of decisions in conflicts received little support.

\footnotetext{
2 At http://kestencgreen.com/responses---role-thinking.xls.

3 Statistical significance tests: We do not provide the findings of tests of statistical significance because there is no evidence that they are relevant to evaluating forecasting methods. With a large enough sample, any difference would be statistically significant even if trivial. In addition, the choice of a null hypothesis is crucial, because significance testers would advocate that it should be adopted when a differences is not statistically significant. In our case we could use any of the competing hypotheses as the null, although, given the evidence to date, simulated interaction would be most appropriate. There are many other reasons for avoiding statistical significance testing (see Armstrong 2007), the most important one being that there is no empirical evidence to support the view that it can improve decision making, whereas it is easy to show harm (Ziliak and McCloskey, 2008; Hauer, 2004).
} 
Table 2

\section{Accuracy of role-thinking forecasts vs. unaided judgment* and chance}

\section{Percent accurate (number of forecasts)}

\begin{tabular}{|c|c|c|c|c|c|c|c|c|c|}
\hline \multirow{3}{*}{$\begin{array}{l}\text { Situation } \\
\text { Distribution Plan }\end{array}$} & \multirow{3}{*}{ Chance } & \multicolumn{4}{|c|}{$\begin{array}{l}\text { Unaided } \\
\text { judgment }\end{array}$} & \multicolumn{4}{|c|}{$\begin{array}{c}\text { Role } \\
\text { thinking }\end{array}$} \\
\hline & & \multicolumn{2}{|c|}{ Novices } & \multicolumn{2}{|c|}{ Experts } & \multicolumn{2}{|c|}{ Novices } & \multicolumn{2}{|c|}{ Experts } \\
\hline & & 5 & (42) & 38 & $(17)$ & 0 & (14) & 0 & (13) \\
\hline Artists Protest & 17 & 5 & (39) & 10 & $(20)$ & 8 & (13) & 0 & (12) \\
\hline 55\% Pay Plan & 25 & 27 & (15) & 18 & (11) & 13 & $(12)$ & 8 & (13) \\
\hline Telco Takeover & 25 & 10 & (10) & 0 & (8) & 13 & $(16)$ & 18 & (11) \\
\hline Journal Negotiations & 25 & 12 & (25) & - & - & 25 & $(12)$ & 30 & (10) \\
\hline Personal Grievance & 25 & 44 & (9) & 31 & (13) & - & - & 36 & (11) \\
\hline Zenith Investment & 33 & 29 & (21) & 36 & (14) & 46 & (13) & 55 & (11) \\
\hline Water Dispute & 33 & 45 & (11) & 50 & (8) & 75 & (16) & 56 & (9) \\
\hline Nurses Dispute & $\underline{33}$ & $\underline{68}$ & $\underline{(22)}$ & $\underline{73}$ & $(15)$ & $\underline{82}$ & (11) & $\underline{73}$ & (11) \\
\hline Averages (unweighted) & 28 & $\overline{27}$ & (194) & $\overline{32}$ & $(106)$ & $\overline{33}$ & (107) & $\overline{31}$ & (101) \\
\hline ex-Journal Negotiations & 28 & 29 & (169) & 32 & (106) & 34 & (95) & 31 & (91) \\
\hline ex-Personal Grievance & 28 & 25 & (185) & 32 & (93) & 33 & (107) & 30 & (90) \\
\hline ex-both & 28 & 27 & (160) & 32 & (93) & 34 & (95) & 30 & (80) \\
\hline
\end{tabular}

*Unaided judgment data are from Armstrong (2001) and Green and Armstrong (2007a).

Information on the novices and the experts who provided unaided judgment forecasts, including their names, is available in Green and Armstrong (2007a) and in Green and Armstrong (2007b). The novices were similar to novices in the role-thinking experiments (undergraduate students) while the experts were in many cases more senior than those in the role-thinking experiments. Additional information on the participants in the earlier work is available at http://www.forecastingprinciples.com/files/pdf/Green-Expert\%2520sources.pdf.

When forecasts for the one conflict for which novice forecasts were not also available (Personal Grievance) are excluded, 30\% of the experts' role-thinking forecasts were accurate compared to $33 \%$ of the novices'. That analysis is on the basis of the broad distinction between the expertise of undergraduate students (novices) and that of mature graduate student navy officers (experts). It takes no account of differences in specialist conflict management experience or of experience with similar conflicts or of the time the participants spent on their analysis. We 
reasoned that participants from among the navy officers who had more of such relevant and direct experience should be better able to use the information we provided and that participants who spent more time on the analysis would also make better use of the information. We therefore next analyzed the effect of prior experience and the time spent on the task for all the role-thinking responses (novices and experts combined) for each conflict using participants' answers to our questions about their experience and the time they spent on the task.

The 67 role-thinking forecasts from those with some experience as conflict management specialists were only a little better at $33 \%$ accurate than the 141 forecasts of those with no experience at $31 \%$ accurate. Experience with conflicts similar to the one being analyzed did help, however; the 102 forecasts of participants with such experience were more accurate than the 102 forecasts of those with no such experience at $38 \%$ accurate compared to $29 \%$.

Spending more time on the role-thinking task was associated with forecasts that were somewhat more accurate; the 82 forecasts derived from analyses of 25 minutes or more were somewhat more accurate at $35 \%$ than the $31 \%$ accurate forecasts out of the 125 forecasts from briefer analyses. However, earlier research had found that forecast accuracy was somewhat negatively related to the time experts spent deriving their forecasts (Green 2005).

\section{Comparison with forecasts from simulated interaction groups}

Armstrong (2001) and Green $(2002,2005)$ used simulated interaction for the aforementioned conflict situations. In contrast to the role thinking treatment, participants in the simulated interaction experiments were given information only on their own role. The participants, who were predominantly undergraduate students, were told to read the role description they had been given, to put on a name badge for the role, and to adopt the role for the duration of the session. Having adopted their roles, they were instructed to read the situation description.

The participants were instructed to introduce themselves to the other participants while in their roles. They were free to meet and to break into smaller groups as often as they considered 
necessary on order to reach a decision. The simulations typically lasted between 30 and 60 minutes.

Each group's decision was taken as a forecast of the actual protagonists' decision.

Note that we are here comparing group versus individual forecasts. However, given that unaided-judgment and role-thinking forecast accuracy differed little from guessing, combining the individual forecasts from those methods would do little to increase accuracy.

The simulated-interaction forecasts were accurate for $60 \%$ of the predictions, which was a substantial improvement over role-thinking forecast accuracy of 32\%. Simulated interaction forecasts were more accurate than the role-thinking forecasts for all of the nine conflicts. In addition, when the simulated interaction forecasts were combined across the groups (an average of 14 groups simulated each situation) the modal decision was accurate for eight of the nine conflicts, or $89 \%$.

\section{Conclusions and recommendations}

Despite being a commonly recommended procedure, there was little prior evidence on whether role thinking can help predict decisions by opponents in conflict situations. We conducted experiments and obtained forecasts of the decisions that would be made in nine diverse conflict situations from 103 undergraduate students (107 forecasts) and from 27 Naval postgraduate students (101 forecasts) who all used a role-thinking method we devised. Role thinking was little better than guessing.

We suspect the poor showing of role thinking is because people are unable to think through complex interactions between protagonists with different roles in ways that realistically represented the situation.

In light of the evidence, there is little support for the use of role thinking. The forecasts are unlikely to be accurate, and decision makers might be lulled into a false sense of confidence that by metaphorically "standing in the other person's shoes" they know what will happen. 
Our findings on role thinking reinforce our findings from previous research: in order to obtain accurate forecasts of the decisions the protagonists will make in a conflict situation, one should ask groups of people to adopt roles and to simulate the interactions between the protagonists.

\section{Acknowledgments}

We thank Jon Czarnecki for conducting role-thinking sessions with his students at the Naval Postgraduate School, and Hans Hansen for access to his undergraduate students. We also thank Kay A. Armstrong, Michael Beyerlein, Don Esslemont, Paul Goodwin, Andreas Graefe, Joe Daly, Nigel Harvey, Philip Schrodt, Bill Zangwill, and three anonymous reviewers for their comments and suggestions, and Soo Lee for her suggestions on the writing.

\section{References}

Armstrong, J. S. (1980). The Seer-Sucker Theory: The Value of Experts in Forecasting. Technology Review, 83 (June/July), 18-24.

Armstrong, J. S. (2001). Role Playing. In J. S. Armstrong (ed). Principles of Forecasting, Boston, MA: Kluwer Academic Publishers, pp.13-30.

Armstrong, J. S. (2007). Significance Tests Harm Progress in Forecasting. International Journal of Forecasting, 23, 321-327.

Babcock, L., Loewenstein, G., Issacharoff, S., \& Camerer, C. (1995). Biased judgments of fairness in bargaining. The American Economic Review, 85, 1337-1343.

Chamberlin, T. C. (1965). The method of multiple working hypotheses. Science, 148, 754-759. (Reprint of an 1890 paper). 
Cyert, R. M., March, J. G., \& Starbuck, W. H. (1961). Two experiments on bias and conflict in organisational estimation. Management Science, 7, 254-264.

Epley, N., Keysar, B., van Boven, L., \& Gilovich, T. (2004). Perspective taking as egocentric anchoring and adjustment. Journal of Personality and Social Psychology, 87, 327-339.

Fischhoff, B. (1975). Hindsight is not equal to foresight: The effect of outcome knowledge on judgment under uncertainty. Journal of Experimental Psychology: Human Perception and Performance, 104, 288-299.

Galinsky, A. D. \& Mussweiler, T. (2001). First offers as anchors: The role of perspective-taking and negotiator focus. Journal of Personality and Social Psychology, 81, 657-669.

Green, K. C. (2002). Forecasting decisions in conflict situations: a comparison of game theory, role-playing, and unaided judgement. International Journal of Forecasting, 18, 321-344.

Green, K. C. (2005). Game theory, simulated interaction, and unaided judgment for forecasting decisions in conflicts: Further evidence. International Journal of Forecasting, 21, 463472.

Green, K. C. \& Armstrong, J. S. (2007a). The value of expertise for forecasting decisions in conflicts. Interfaces, 37, 287-299.

Green, K. C. \& Armstrong, J. S. (2007b). Structured analogies for forecasting. International Journal of Forecasting, 23, 365-376.

Hauer. E. (2004). The harm done by tests of significance. Accident Analysis and Prevention, 36, 495-500.

Milgram, S. (1974). Obedience to Authority. New York: Harper \& Row.

Mixon, D. (1972), Instead of deception. Journal of the Theory of Social Behavior, 2, 145-177.

Morris, E. (2003). The Fog of War (documentary film). Culver City, CA: Sony Pictures Classics. 
Nalebuff, B. J. \& Brandenburger A. M. (1996). Co-opetition, New York: Doubleday.

Rothbart, M. and Hallmark, W. (1988). In-group-out-group differences in the perceived efficacy of coercion and conciliation in resolving social conflict. Journal of Personality and Social Psychology, 55, 248-257.

Tetlock, P. E. (2005). Expert Political Judgment. Princeton University Press: Princeton.

Ziliak, S. T. \& McCloskey, D. N. (2008). The cult of statistical significance: How the standard error costs us jobs, justice, and lives. Ann Arbor, MI: University of Michigan Press. 


\section{Appendix A: Example situation description}

\section{International Water Dispute}

Today is June 3, 1975. Two poor and arid Asian countries, Midistan and Deltaland, are in dispute over access to the waters of the River Fluvium. The river rises in Uplandia, whose plentiful rain contributes at least $90 \%$ of the flow. It then runs through Midistan - where the scanty rainfall makes up the rest of the flow - and then on through Deltaland to the sea. Relations between the two disputants have deteriorated badly, and the Government of Concordia has stepped in, in an attempt to mediate an agreement. Uplandia is not involved in this dispute.

\section{Background}

Both Midistan and Deltaland depend heavily on Fluvium water for irrigation. Midistan also uses the river for generating electricity. Deltaland has exploited the waters of the Fluvium since ancient times. Uplandia and Midistan, on the other hand, started to make substantial use of the river's water only about ten years ago. Eighteen months ago, Uplandia began filling its new dam at Updama. A few months later the new Soviet-constructed dam at Mididam in Midistan became operational.

Midistan and Deltaland are ruled by leaders who came to power after military coups. They are loosely aligned to the Soviet Union. Their armed forces are similar in size - both are large and battle-hardened.

\section{Recent developments}

On April 7, Deltaland accused Midistan of putting at risk the lives of the three million Deltaland farmers dependent on the water of the Fluvium by diverting excessive volumes from the river. The Deltaland News Agency reported the protest came "as a result of the lack of response by the Midistani Government to all efforts exerted by the Deltaland Government for years to reach an agreement...". Two days later, the Deltaland Government issued a statement saying it would take whatever steps were necessary to ensure access to the waters of the Fluvium and would hold Midistan responsible for any harm to Deltalandish farmers. A congress of Midistani political leaders, on the same day, condemned the Deltaland regime for plotting with enemies of Midistan and betraying the common heritage of the two countries. There were reports that 200 military and civilian leaders had been arrested, in the lead-up to the conference, on charges of plotting against the Midistani Government. Those arrested included the director of a news agency and a former director of Midistani television.

The Midistani Government explained their position on the disagreement over access to Fluvium water in an official statement released on April 19. In the statement, Midistan blamed the current crisis on the Deltaland Government's unwillingness to enter in good faith into tripartite negotiations with Midistan and Uplandia for a permanent agreement over sharing the water. Deltaland instead had conducted secret negotiations with Uplandia. Midistan claimed to have reached provisional agreement with Deltaland two years before for the flow of water during the winter just gone, but had stipulated that the agreed volume would have to be revised when the Updama dam began to fill. Midistan accused Deltaland of avoiding negotiations over this issue when Uplandia had commenced filling the Updama dam in January of last year.

The statement also claimed that, despite substantial reductions in, and interruptions of, the flow of water out of Uplandia, Midistan had allowed $70 \%$ of the water received to flow on into Deltaland, had released an additional 200 million $\mathrm{m} 3$ (0.7\% of the usual annual inflow) during the middle of last year in response to a request by Deltaland and, during last winter had let $75 \%$ of water from Uplandia flow on to Deltaland. Further, Midistan accused Deltaland of failing to modernise its irrigation methods in order to make more effective use of the water it does receive.

In response, Deltaland maintained its claims that more water than was required for electricity generation had been withheld and that only half of the water to which Deltaland was entitled had been received.

Claims and counter-claims by Midistan and Deltaland continued through April and May, as did mediation efforts by neighbouring countries including the wealthy regional leader, Concordia. Midistan accused Deltaland of assassinations and mass executions of dissidents on May 7 and, a week later, closed its airspace to Deltalandish aircraft in response to mistreatment of Midistani airline personnel employed in Deltaland. On May 25, Midistan ordered the immediate closure of one of Deltaland's consulates in Midistan. On May 28 a Midistani military official in Deltaland was stabbed and, on May 29, Midistan accused the Deltalandish government of executing 80 government opponents. By June 2, there were reports that both sides had moved troops to the border between the countries and that Deltaland had threatened to bomb the Mididam dam. In response to the deteriorating situation, Concordia renewed its efforts at mediation and a meeting between ministers from the three countries is to be held.

\section{The meeting}

Today, Government ministers and officials from the Midistan, Deltaland, and Concordia will meet to try to resolve the dispute. Those present at the meeting will be a senior Minister from the Kingdom of Concordia, and the Foreign Ministers of the Republics of Midistan and Deltaland each accompanied by a military adviser. A statement will be issued at the end of the meeting. The statement may be one of three alternatives. The gist of these statements are as follows:

(a) Midistan has decided to release additional water in order to meet the needs of the Deltalandish people

(b) Deltaland has ordered the bombing of the dam at Mididam to release water for the needy Deltalandish people

(c) Deltaland has declared war on Midistan. 
Role of Republic of Midistan Foreign Minister - Mohammad Fareed

A crisis over access to water is brewing between the poor Asian nation, Midistan, and the neighbouring Republic of Deltaland. As Midistan's Foreign Minister, you are attending a meeting with your Deltaland counterpart (Daud Fawaz) and a senior Minister from the Kingdom of Concordia - a wealthy regional power. The Minister from Concordia (Karim Khalid) will attempt to mediate an agreement. The crises has already led to military preparations by both sides. Before joining the meeting you will discuss objectives and strategy with the military adviser who has accompanied you - General Mustafa Ahmad.

As far as you and your government are concerned, Midistan has acted responsibly in a difficult situation that is not of Midistan's making. You are directly responsible to your President who, along with you and the rest of the Midistan government, came to power after a military coup.

Role of Republic of Midistan Military Adviser - General Mustafa Ahmad

A crisis over access to water is brewing between the poor Asian nation, Midistan, and the neighbouring Republic of Deltaland. You are attending a meeting with Deltaland government representatives and a senior Minister from the Kingdom of Concordia - a wealthy regional power. The Minister from Concordia (Karim Khalid) will attempt to mediate an agreement. The crises has already led to military preparations by both sides - troops have been moved to the vicinity of the common border. Your role is to support and advise your Foreign Minister (Mohammad Fareed) with whom you will discuss objectives and strategy before you both join the meeting.

As far as you and your government are concerned, Midistan has acted responsibly in a difficult situation that is not of Midistan's making. You are directly responsible to your Foreign Minister who, along with you and the rest of the Midistan government, came to power after a military coup.

\section{Role of Republic of Deltaland Foreign Minister - Daud Fawaz}

A crisis over access to water is brewing between the poor Asian nation, Deltaland, and the neighbouring Republic of Midistan. Deltaland has a long history of using the waters of the River Fluvium and is heavily dependent on the river for agriculture and drinking water. Midistan has recently built a large dam and the Fluvium's flow into Deltaland has been curtailed. As Deltaland's Foreign Minister, you are attending a meeting with your Midistan counterpart (Mohammad Fareed) and a senior Minister from the Kingdom of Concordia - a wealthy regional power. The Minister from Concordia (Karim Khalid) will attempt to mediate an agreement. The crises has already led to military preparations by both sides. Before joining the meeting you will discuss objectives and strategy with the military adviser (General Dirwar Ali) who has accompanied you.

You are directly responsible to your President who, along with you and the rest of the Deltaland government, came to power after a military coup.

\section{Role of Republic of Deltaland Military Adviser - General Dirwar Ali}

A crisis over access to water is brewing between the poor Asian nation, Deltaland, and the neighbouring Republic of Midistan. Deltaland has a long history of using the waters of the River Fluvium and is heavily dependent on the river for agriculture and drinking water. Midistan has recently built a large dam and the Fluvium's flow into Deltaland has been curtailed. You are attending a meeting with Midistan government representatives and a senior Minister from the Kingdom of Concordia - a wealthy regional power. The Minister from Concordia (Karim Khalid) will attempt to mediate an agreement. The crises has already led to military preparations by both sides - troops have been moved to the vicinity of the common border. Your role is to support and advise your Foreign Minister (Daud Fawaz) with whom you will discuss objectives and strategy before you both join the meeting.

You are directly responsible to your Foreign Minister who, along with you and the rest of the Deltaland government, came to power after a military coup.

\section{Role of Kingdom of Concordia Senior Minister - Karim Khalid}

Two poor neighbours of the wealthy Kingdom of Concordia appear to be edging closer to war in a dispute over access to the waters of a river that flows from one (Midistan) to the other (Deltaland). Your Kingdom has a traditionally played a paternal role in the region, and has an interest in preserving peace. To that end, you have called a meeting, which is being attended by Midistan and Deltaland representatives, with the hope that your mediation will lead to a peaceful solution to the crisis. Midistan is represented by Foreign Minister Mohammad Fareed and Military Adviser General Mustafa Ahmad. Deltaland is represented by Foreign Minister Daud Fawaz and Military Adviser General Dirwar Ali. 


\section{Appendix B: Example role-thinking questionnaire}

\section{International Water Dispute}

1) A person's role can make a big difference to how he or she views a situation, so it can be difficult to predict what decisions will be made when people interact with each other. In the following table,please indicate which decision you think each party in the situation just described would prefer to be made andassess how likely it is that each party's preferred decision will actually occur.

For each party in the conflict, please use your judgment to:

(A) (i) select from the following list the decision or decisions the party would prefer to see emerge from today's meeting:

a. Midistan has decided to release additional water in order to meet the needs of the Deltalandish people

b. Deltaland has ordered the bombing of the dam at Mididam to release water for the needy Deltalandish people

c. Deltaland has declared war on Midistan

(ii) explain why you think the party prefers that decision or those decisions

(B) (i) explain how you think the party would go about trying to achieve its most-preferred decision

(ii) rate the chances that the decision will be made, out of $10(0=$ almost no chance...10 = almost certain $)$

\begin{tabular}{|c|c|c|}
\hline Party & $\begin{array}{l}\text { (A)(i) Party's preferred decision(s) from a-c, abowe } \\
\text { (ii) Why preferred }\end{array}$ & $\begin{array}{l}\text { (B)(i) How party would try to achieve most.preferred decision } \\
\text { (ii) Chanoes that mostpreferred decision will be made[0-10) }\end{array}$ \\
\hline Midistan & (i) $[ـ$ & (ii) [ ] \\
\hline Deltaland & (i) $\left[\_\right.$] (ii) & (ii) [ ] $]$ \\
\hline Concordia & (i) $\left[\_\right.$(ii) & (ii) [ ] \\
\hline
\end{tabular}

2) Roughly, how long did you spend on this task?

[include the time you spent reading the description and instructions\}

3) How likely is it that taking more time would change your answers to (B)(ii)? $\{0=$ almost no chance $(1 / 100) \ldots 10=$ almost certain $(99 / 100)\}$

4) Do you recognise the actual conflict (e.g. the real parties involved)? Yes L] No L] If so, please identify it:

5) How many people did you discuss this forecasting problem with?

6) Roughly, how many years experience do you have as a conflict management specialist? 